\title{
INCONMENSURABILIDAD, EXPERIENCIA DE LO EXTRAÑO Y COMUNIDAD CARNAL EN SIMONE WEIL Y LA FENOMENOLOGÍA CONTEMPORÁNEA
}

\author{
ESTEBAN A. GARCíA \\ INSTITUTO DE FILOSOFIA \\ UNIVERSIDAD DE BUENOS AIRES
}

A lo largo de todo su desarrollo, pero particularmente al intentar en sus últimos escritos reformular sus problemas en términos hermenéuticos, la filósofa Simone Weil se enfrentó al problema de la diversidad del sentido. En este trabajo nos propondremos, en primer lugar, mostrar de qué modo la necesidad de hacer frente a este problema deriva de una matriz tipo fenomenológico-hermenéutico presente en su pensamiento. Veremos de qué modo debió la fenomenología contemporánea tratar el mismo problema a partir de la investigación del enigmático aparecer de lo "extraño" (Fremdeln), investigación de la que Husserl mismo sentó las bases al analizar la experiencia de la alteridad humana en sus Meditaciones cartesianas. Intentaremos por último, de este modo dialógico, y considerando paralelamente a algunos referentes de la discusión filosófica contemporánea en torno al relativismo cultural, marcar algunas direcciones en que es posible investigar su superación. Éstas apuntan fundamentalmente hacia el reconocimiento de un estrato elemental común de la experiencia en el que existe, en virtud del nacimiento, la sexualidad, la muerte, una comunicación y una comunidad carnal que, sin pasar por alto las particularidades y diferencias intersubjetivas, funda a la vez toda comprensión de lo extraño.

En su "Essai sur la notion de lecture" (1914) Weil constata que la experiencia perceptiva sólo permite ser descrita como la conjunción de sujeto y objeto, actividad y pasividad. ${ }^{2}$ Lo que aparece como objeto está constituido subjetivamente sin por ello dejar de parecerme trascendente. Weil señala

1 Simone Weil, "Essai sur la notion de lecture", Études philosophiques, no.1, enero-marzo 1946, pp. 13-16. 
que toda experiencia es análoga a la de la lectura de un texto, en la que el sentido surge del encuentro de lo escrito con las capacidades y habilidades del lector (piénsese por ejemplo en el destino de un mismo texto en manos de alguien que conoce el idioma en que está escrito y en las de quien no lo conoce). Toda experiencia se desarrolla entonces en este ámbito ambiguo, intermedio y dinámico que es el del sentido. Una consecuencia inmediata de este planteamiento es que ya no es posible concebir la verdad de la experiencia como reflejo adecuado del objeto sobre el sujeto, puesto que ambos términos de la experiencia ya no permiten ser concebidos de modo independiente uno de otro. A esto se suma el hecho de que existe una diversidad de sentidos leídos que no concurren en una experiencia articulada ni pueden coexistir sin interferencias, sino que se contradicen, contrastan, se oponen o parecen excluirse mutuamente: tal es el caso de la percepción de un hombre en la oscuridad, percepción que al acercarnos cambia repentinamente por la de un árbol. De acuerdo con el enfoque hermenéutico adoptado por Weil ya no es posible hablar en tal caso de una "corrección" de una "ilusión sensible", sino sólo de la sucesión de dos lecturas diferentes, de un "cambio de lecturas". Ambas lecturas son igualmente válidas, lo que hace que sean a la vez igualmente arbitrarias: "Cuando nos elevamos a la noción de lectura, aparece lo arbitrario." 2 Es natural entonces que el "Ensayo sobre la noción de lectura" culmine planteándose el problema de la existencia y determinación de un criterio de valor y verdad de las diversas lecturas: "Los textos de los cuales las apariencias son los caracteres que se apoderan de mi alma, la abandonan, son reemplazados por otros ¿Valen más unos que otros? ¿Son más verdaderos unos que otros? ¿Dónde hallar una norma?"3

En algunos de sus últimos escritos Weil utiliza el término "inconmesurabilidad" 4 para aludir a esta ausencia de una medida o razón (logos) común a la multiplicidad y diversidad que constituye la experiencia humana. El término es tomado de su uso matemático: la hipotenusa de un triángulo rectángulo isósceles es "inconmensurable" con su lado en tanto no existe una unidad de longitud contenida un número entero de veces sin resto en el par; i.e.: no existe entre ellos una medida común. ${ }^{5}$ La analogía con la

2 S.Weil, Oeuvres complètes VI 1, Gallimard, París, 1994, p. 309.

3 S.Weil, "Essai sur la notion de lecture", op cit., p. 18.

4 Particularmente en "À propos de la doctrine pythagoricienne", en Intuitions pré-chrétiennes, La Colombe, París, 1951, pp. 109-171. Cfr. también "Notas sobre Filolao", en La fuente griega, Sudamericana, Buenos Aires, 1961, pp. 148-155.

5 Unos veinte años más tarde (desde 1962) el término se haría usual en la discusión filosófica cuando T. Kuhn y P. Feyerabend simultánea aunque independientemente lo usaron como una metáfora para describir, en la historia de la ciencia, la relación entre teorías científicas sucesivas. Cfr. también T. Kuhn, "Conmensurabilidad, comparabilidad y comunicabilidad", en ¿Qué son las revoluciones científicas?, Paidós, Barcelona, 1989, pp. 95, 96. 
matemática y la geometría sirve a Weil no sólo para plantear el problema sino también, como se verá más adelante, para orientar su búsqueda de una solución. Peter Winch da una clara definición del problema diciendo que al hablar de "inconmensurabilidad" Weil está en realidad llamando la atención sobre "un número de diferentes dificultades que enfrentamos al tratar de dar sentido de la vida humana", 6 una vez que ésta se ha revelado como una pura diversidad. Podría compararse esta situación con aquella que resulta de la descripción wittgensteiniana de los "juegos de lenguaje" como si no tuvieran nada en común unos con otros. ${ }^{7}$ No hay un super-juego del que participen todos los juegos, ni siquiera por su característica de "ser juegos" (ya que esto no significa que tengan algo en común, sino sólo que percibimos entre ellos "aires de familia", dice Wittgenstein). Esto significa la imposibilidad de dar una definición unívoca de algo que sería propio del "lenguaje" así como de la "vida humana", porque éstos no son más que pura labilidad, diversidad de juegos y modos de vida: "Cuando oímos a un chino -escribe Wittgenstein - nos inclinamos a considerar su lenguaje como un balbuceo inarticulado. Pero quien entiende el chino reconocerá allí el lenguaje. Así, con frecuencia, no puedo reconocer al Hombre en el hombre." 8

La fenomenología contemporánea se ha visto llevada a tratar el problema de la inconmensurabilidad, lo cual puede verse como una consecuencia necesaria de algunas de las formulaciones que están en su base. Si bien toda la filosofía de Husserl constituye explícitamente una crítica al relativismo en todas sus formas (psicologista, historicista, naturalista, etc.), David

6 p. Winch, Simone Weil: "The Just Balance", Cambridge University Press, Cambridge, 1989, p. 161. Las cursivas son nuestras.

7 Cfr. L. Wittgenstein, Investigaciones filosóficas, $\S \S 65,66$ y 67 . En un texto de 1941 dedicado a la historia de la ciencia Simone Weil recurre a la noción de "juego" y usa como imágenes para esclarecer el concepto algunos de los mismos ejemplos que se refieren a la "lectura". Así, cada lectura podría ser vista como si participara de un "juego" particular, "tal como el juego de dados, de cartas, de damas: el jugador se da a sí mismo un universo finito por medio de reglas fijas que impone a sus acciones, y cada vez que va a jugar le es dado solamente elegir entre un pequeño número de posibles". De modo semejante a los conceptos de Sprachspiel/Lebensform en Wittgenstein, un juego organiza un espectro limitado de posibilidades de la experiencia, si bien es esencial para jugar el juego el que no sea posible tener una conciencia y un manejo total de estas posibilidades. En este sentido escribe Weil que "la complicación es esencial al interés y no se jugaría si se pudiera tener de hecho en el espíritu todas las partidas posibles; pero por más que sobrepase el alcance del espíritu humano como si fuera infinito, es sin embargo finito, y esto es esencial al juego" (S. Weil, Sur la science, Gallimard, París, 1966, pp. 68 ss.). Esta lógica del juego significa que nuestra experiencia en tanto lectura está referida a ciertas reglas "leo las sensaciones según tal ley o según tal otra ley"; Oeuvres complètes VI 1, ibid., p. 295) las cuales, a la vez que delimitan un campo de posibilidades, nos son en parte invisibles en sus implicaciones, por lo que no nos es posible percatarnos de esta limitación.

8 L. Wittgenstein, Aforismos, cultura y valor, Espasa Calpe, Madrid, 1996, p. 31. 
Carr ha sostenido que ciertos aspectos fundamentales de su fenomenología -a saber, las doctrinas relativas a "la búsqueda de lo dado", "el objeto como intencionado" y "la conciencia como Gestalt temporal"- pudieron sentar simultáneamente las bases de un planteamiento inconmesurable y aun relativista. Ya cuando en la primera Investigación Lógica Husserl habla de una "intención que anima" a ciertas marcas en el papel o a ciertos sonidos advierte que uno se ve tentado a pensar en un proceso tal como si "'la conciencia primero se dirige a las sensaciones, luego las convierte en objetos perceptuales' [...]. Pero Husserl rechaza esta visión, como lo hará más tarde en Ideas". ${ }^{9}$ La sensación no es en ningún caso objeto de la conciencia, y a la vez lo intencionado por la conciencia recibe una nota que tradicionalmente se atribuye a la sensación: la inmediatez. El sentido "leído" en la experiencia recibe idéntica caracterización en el análisis de Weil quien ya en sus lecciones de filosofía de Roanne (1933-1934) esbozaba una crítica a la sensación como abstracción frente a la experiencia vivida en la que el sentido se da inmediatamente. ${ }^{10}$ Luego en su ensayo sobre la lectura observará que del mismo modo que al leer "sólo lo que leemos nos es dado; no vemos las letras", vivienciamos el sentido y no las sensaciones, pero el sentido aparece tan inmediatamente como una sensación. ${ }^{11}$ Igualmente, para Husserl lo dado está, como indica Carr, "ahí para nosotros anteriormente a la abstracción y la actividad mental explícita y no se llega a él por ninguna actividad tal". Esta concepción de lo dado dejaría, según Carr, la puerta abierta al relativismo puesto que "el concepto de lo inmediato [unmediated] en el sentido puramente descriptivo o fenomenológico no sólo no provee un nexo cognitivo sólido con una realidad independiente existente por sí misma; ni siquiera implica ninguna seguridad de acuerdo intersubjetivo, al menos, no en el sentido universal necesario para superar el relativismo. ${ }^{12}$ Según Carr, esto mismo se extiende a las filosofías de Merleau-Ponty y Heidegger en cuanto prosiguen desarrollando, cada uno a su modo, esta misma noción de una experiencia originaria inmmediata del sentido, y en ellos aparece ya explícitamente sugerida la consecuencia de que "el mundo puede variar, si no de individuo a individuo, quizás de una comunidad o periodo histórico a otro". ${ }^{13}$

Por otra parte, la noción de objeto intencionado aparece ligado en la fenomenología a la perspectiva: la doctrina del noema expuesta en Ideas

9 David Carr, "Phenomenology and Relativism", en Interpreting Husserl. Critical and Comparative Studies, Martinus Nijhoff Publishers, Dordrecht/Boston/Lancaster, 1987, p. 33.

$10 \mathrm{~S}$. Weil, Leçons de philosophie, Plon, París, 1989.

$11 \mathrm{~S}$. Weil, "Essai sur la notion de lecture", op. cit., p. 14.

12 D. Carr, op. cit., p. 33.

13 Ibid., p. 34. 
implica por ejemplo que el objeto "tal como es intencionado" apunta siempre más allá de sí en tácita referencia a otras posibles intenciones del mismo objeto. Es inherente a la experiencia percibir el objeto a través de cierta perspectiva, hay una inadecuación que es esencial a la experiencia, lo cual ya observaba Weil desde sus primeros escritos al analizar la percepción de un cubo: en la percepción - leemos en las Leçons de philosophie- "las cosas aparecen ya como independientes de nosotros, pero vemos todo desde cierta perspectiva". ${ }^{14}$ Carr continúa mostrando que es esta misma intuición básica de la fenomenología la que puede verse implícita o en paralelo con la noción de "tomar por" o "ver como" (noción analizada por Wittgenstein en la segunda parte de sus Investigaciones filosóficas, a la que Peter Winch ha comparado con el concepto weiliano de "lectura"), ${ }^{15}$ en la noción del "como" hermenéutico de Heidegger y en la de Merleau-Ponty de "perspectiva" o "punto de vista". De todas ellas podemos deducir, según Carr, las mismas implicaciones relativistas que derivan de la de "objeto intencional". ${ }^{16}$ Nos hallamos, al parecer, limitados a vivienciar una experiencia posible entre otras diversas, y hemos dejado atrás el criterio exterior que podría proveer la presencia de un mundo independiente de nuestra experiencia.

Esta situación básica explicitada por la fenomenología es la condición que posibilita que la experiencia humana sea una experiencia expuesta a la vivencia de "lo extraño". Experimentamos un objeto o una situación como extraños, según Husserl, en cuanto tiene para nosotros "la accesibilidad verificable de lo originalmente inaccesible", ${ }^{17}$ es decir, en cuanto el sentido de su aparecer se nos sustrae parcialmente de modo original. Una sustracción tal es esencial al aparecer de todo objeto en cuanto sólo aparece en una u otra perspectiva, de modo que la experiencia de todo objeto reviste un núcleo de extrañeza, pero la extrañeza de las cosas —e incluso la de mí mismo- es para Husserl "secundaria" o "tomada de prestado" respecto de la extrañeza de otro sujeto, en cuanto, como indica la Quinta Meditación Cartesiana, sólo el otro es para mí "originalmente inaccesible" mientras que para percibir otros aspectos de las cosas sólo necesito cambiar de lugar. ${ }^{18}$ Como indica B. Waldenfels, "si el mundo de las cosas reviste características de extrañeza, esto sucede en la medida en que remite a experiencias extrañas, que, a pesar de toda comunalización, nunca se recubren plenamente

14 S. Weil, Leçons de philosophie, op. cit., p. 209.

15 Peter Winch, Simone Weil: The Just Balance, op. cit., 1989.

16 D. Carr, op. cit., pp. 36 ss.

17 Edmund Husserl, Meditaciones cartesianas, trad. de José Gaos-Miguel García Baro, Fondo de Cultura Económica, México, 1996, p. 178.

18 E. Husserl, op. cit., pp. 172 ss. 
con las mías". ${ }^{19}$ La cuestión de la extrañeza del otro hombre es clave en la fenomenología de Husserl, en cuanto, como lo ha visto Merleau-Ponty, convergen modélicamente en ella "todos los problemas de la trascendencia. Que se trate de mi cuerpo, del mundo natural, del pasado, del nacimiento o de la muerte, la cuestión estriba siempre en saber cómo puedo estar abierto a unos fenómenos que me sobrepasan y que, no obstante, nada más existen en la medida en que los recojo y vivo". ${ }^{20}$

Puede observarse ya que esta "inaccesibilidad originaria", esencial, que comporta la alteridad humana -en cuanto " 'experiencia de lo otro', como ajeno, como apresentado pero ni dado ni capaz nunca, por principio, de darse él mismo [ni su particular experiencia del mundo] originalmente en mi esfera primordial" - ${ }^{21}$ se liga a la cuestión de la inconmensurabilidad en cuanto abre una diferencia insalvable entre mi experiencia y la del otro, cuando ya se ha revelado inválido el recurso al criterio exterior de un mundo desligado de una experiencia subjetiva. El mundo se hallaría ahora fragmentado en mi mundo y el suyo, y sólo podría recuperar su unidad si esta diferencia intersubjetiva es de alguna manera superada. En este punto el problema para Husserl podría ser planteado entonces como el de recuperar la universalidad y objetividad - la racionalidad - del sentido, pero sin hacer caso omiso del dato irrecusable de esta diversidad esencial al sentido. La atención prestada a la constitución de la comunidad intermonádica y el correlativo recurso a un a priori estructural del mundo de la vida pueden ser abordados desde esta perspectiva, como se verá más adelante. Es cierto, por una parte, que hemos enfatizado la caracterización husserliana de la extrañeza del otro mientras que Husserl reconocerá en seguida que ésta es segunda respecto de mi originaria comunidad con él: el otro no aparece originariamente como "frente a mi", sino "conmigo"22 en cuanto la parificación que le da sentido implica primeramente, como se verá, una especie de "contagio intencional", un "mutuo suscitarse vivo", un "solaparse", un "entretejimiento" de mí y el otro. ${ }^{23}$ Sin embargo, no es menos cierto que, como ha notado B. Waldenfels, con la paradójica definición husserliana de la alteridad humana como accesibilidad de lo no-accesible o no-originalidad original difícilmente podría haberse ido más lejos en la radicalización de su

19 Bernhard Waldenfels, "La experiencia de lo estraño en la fenomenología de Husserl", trad. de Graciela R. de Walton y Roberto J. Walton, Escritos de filosofía, no. 21-22, enerodiciembre 1992, p. 11.

20 Maurice Merleau-Ponty, "El otro y el mundo humano", en Fenomenología de la percepción, trad. de J. Cabanes, Península-Planeta, Barcelona, 1994, p. 374.

21 E. Husserl, Meditaciones cartesianas, op. cit., pp. 219, 220.

22 Ibid., p. 196.

23 Las expresiones aparecen en E. Husserl, op. cit., §§51, 52, ibid., pp. 176, 177. 
extrañeza. Apenas se ha ido un paso más allá al hablar, como Merleau-Ponty en su obra tardía, de una "presentación originaria de lo no-originariamente presentable", o, como Lévinas, de la ausencia constitutiva de la presencia del otro, o de la relación no-relacionante en que se me aparece sustrayéndose a mí, enigmáticamente. ${ }^{24}$

Antes de avanzar en la determinación de los múltiples aspectos del problema y los posibles modos de superarlo será útil realizar, a modo de excursus, ciertas precisiones respecto de su radicalidad, considerando críticamente algunas tesis que tienden a amortiguar el choque de lo extraño y las diferencias intersubjetivas. D. Davidson ha dado buenos argumentos para descartar cualquier teoría de la inconmensurabilidad que entienda a esta última como la intraducibilidad de lenguajes o esquemas conceptuales y que suponga un dualismo entre esquema (o lenguaje) y realidad. ${ }^{25}$ Como lo ha visto $\mathrm{N}$. Sánchez Durá, la traducción ha sido el ejemplo más influyente y más usado como modelo desde posiciones etnocéntricas, para las cuales ya no funciona como una manera figurada de referirse a la descripción interpretativa de una vida o cultura ajena, sino de modo tal que "se piensa que comprender una cultura diferente es o consiste en traducir los enunciados de los hablantes de esa comunidad que se pretende comprender. De forma que, al final, con lo que nos encontramos es con una reducción de la conducta significativa a la mera conducta verbal de los hablantes". ${ }^{26}$ Una vez aceptado que "comprender al otro es traducirlo", el paso siguiente de este tipo de argumentación es observar que "para traducirlo hay que suponerle tanta afinidad con nosotros que prácticamente es 'uno de los nuestros' ". ${ }^{27}$ Como expresa T. Kuhn en su respuesta a Davidson, la inconmensurabilidad real se plantea precisamente cuando se ha abandonado tal dualismo representacionista (como el que en última instancia estaría implícito en un modelo de traducción) en favor de una teoría de la interpretación (como es el caso del enfoque fenomenológico) y cuando se ha reemplazado la noción de traducción por la de aprendizaje. ${ }^{28}$ Esto es justamente lo que sucede en la evolución del pensamiento de Weil durante la segunda mitad de la

24 Cfr. B. Waldenfels, "La experiencia de lo extraño en la feonomenología de Husserl", op. cit., p. 10.

25 D. Davidson, "De la idea misma de un esquema conceptual", en De la verdad y de la interpretación, Gedisa, Barcelona, 1990. La conclusión a la que arriba este autor en este trabajo es que "no podríamos estar en condiciones de juzgar que otras personas tienen conceptos o creencias radicalmente diferentes de los nuestros" (p. 202).

26 Nicolás Sánchez Durá, "Miradas fulgurantes y traductores caritativos", en Mirar con cuidado. Filosofía y escepticismo, Pre-Textos, Valencia, 1994, p. 262.

27 Ibid., p. 265.

28 Thomas Kuhn, "Conmensurabilidad, comparabilidad y comunicabilidad", en ¿Qué son las revoluciones científicas?, Paidós, Barcelona, 1989. 
década de 1930. La reflexión de Weil sobre la significación tendió a dejar de expresarse en términos de signo y significado cuando pasó a un primer plano su teoría de la lectura de significaciones. Al definir esta noción intentó mostrar cómo mediante la inmediatez que le es propia, como ya vimos, la distinción entre significante y significado, al igual que la de sensación y sentido, se torna relativa y absracta: cuando intentamos señalar el elemento material del signo no hacemos más que "leer" otro sentido (por ejemplo, el de las letras del alfabeto). ${ }^{29} \mathrm{El}$ "giro hermenéutico" supone también un "giro holístico": un elemento del lenguaje no significa por su referencia a un elemento de otro dominio (virtual o real), sino por su integración en una red contextual de términos interrelacionados (el alfabeto, para continuar el ejemplo de las letras de Weil). Así dice Weil, por ejemplo, que una lectura está determinada en gran medida por un contexto pragmático que me sitúa "en relación con", es decir, por el "encontrarse en tal o cual situación (por ejemplo delante de una máquina, en una prisión, con una espada en la garganta, con la espada en la mano, con o sin dinero en el bolsillo, etc.)" ${ }^{30}$ El cambio de lectura es visto como mediado por un proceso similar al de aprender un idioma nuevo ("como cuando aprendemos el alfabeto de una lengua extranjera... ", dice Weil en sus notas sobre la lectura). ${ }^{31}$ Este aprendizaje ya no puede ser equiparado enteramente a una traducción, porque ésta supondría que cierta palabra o grupo de palabras (o ciertas estructuras del "esquema conceptual", en la terminología de Davidson que parece por sí misma inadecuada para referirnos a la "lectura") se refieren al mismo elemento o grupo de elementos en la realidad, y ya se ha descartado tal teoría de la referencia. Como escribe T. Kuhn, "cuando la traducción no es factible, se requieren dos procesos que son muy diferentes: interpretación y aprendizaje del lenguaje. Estos procesos no son arcanos. Historiadores, antropólogos y quizá los niños se dedican a ellos todos los días". ${ }^{32}$ Este aprendizaje tiene que ver con hábitos o entrenamientos que nos permiten integrarnos o simplemente nos arrojan a nuevas interpretaciones o sistemas de interpretación. De modo semejante, también Husserl concibe la adquisición y el pasaje de un sistema cultural de interpretación (de un "mundo") a otro de modo más radical y vívido que el de una mera traducción, como una "intro-educación" o un "intro-vivir":

Así, como al ser niño, fui educado dentro de mi mundo generativo de hombres, así también, cuando quiero entender a los chinos y al mundo chino debo ser in-

S. Weil, "Essai. .. ", op. cit., p. 14.

30 S. Weil, Oeuvres complètes VI 1, op. cit., p. 296.

31 Ibid., p. 411.

32 T. Kuhn, op. cit., p. 133. 
troeducado (hineinherzogen); debo, introviviendo (hineinlebend), adquirir para mí las apercepciones del mundo extraño, como quiera que, y hasta donde, ello sea posible. ${ }^{33}$

Resulta importante subrayar como conclusión de lo recién expuesto el hecho de que el problema de la comprensión o (incomprensión) entre sujetos y comunidades no puede abordarse mediante el modelo de la traducción porque [este problema] se plantea, tanto para Weil como para la fenomenología, aun en un nivel más primario que el del lenguaje o el pensamiento: la percepción y la praxis son las que se han tornado hermenéuticas. Como señala N. Sánchez Durá, "la inconmensurabilidad afecta no sólo a cuestiones verbales, a enunciados y a los conceptos que entretejen, sino también a aspectos y prácticas que no pueden ser reducidos a las meras enunciaciones verbales para las cuales se buscan equivalencias en los manuales de traducción de Quine y Hollis". ${ }^{34}$ Tanto Weil en su teoría de la lectura como la fenomenología de Husserl describieron un ámbito de sentido existente en experiencias humanas pre-lingüísticas, "la experiencia muda que debe ser llevada a la expresión de su propio sentido". ${ }^{35}$ Podría darse la razón a KarlOtto Apel cuando observa que es precisamente la postulación de esta área previa al lenguaje como ámbito fundamental del sentido lo que posibilita la radicalización de las diferencias intersubjetivas exponiéndose, aun sin desearlo, al relativismo. ${ }^{36}$ Pero ya no resulta posible escapar del problema, como él propone, volviendo a poner como clave del sentido, como núcleo de la experiencia humana, a la comunicación lingüística y la argumentación con sus supuestos principios normativos universales implícitos -el "paradigma pragmático-lingüístico" del "yo argumento"-, puesto que el lenguaje no podría más que reflejar la fragmentación y la diversidad de la experiencia que le da sentido. A la inversa, sólo atendiendo al problema originario de la diversidad inconmensurable del sentido de la experiencia se hace posible -y es necesario- abordar el problema de la comunicación. Veremos que tanto Husserl como Weil investigarán, de modos diversos, la posibilidad del encuentro y la comunidad intersubjetivos profundizando aún más en el ámbito de la experiencia primordial descubierta, de un modo que ya es

33 E. Husserl, Ms. A VI 9, cit. por Dieter Lohmar, "La experiencia de lo extraño. Análisis fenomenológicos sobre el modo de la experiencia de la extrañeza en culturas extrañas" (trad. de G. Ralón de Walton y Roberto J. Walton), Escritos de filosofía, año XV, no. 29-30, enerodiciembre, 1996.

34 N. Sánchez Durá, op. cit., p. 267.

35 Hua., I, 77, cit. en R. Walton, "La consideración interior de la historia en la fenomenología trascendental", Escritos de filosofía, año XVI, no. 31, enero-junio 1997, p. 156.

36 Karl-Otto Apel, "¿Es la filosofía del lenguaje una clave para la fundamentación de la ética?", Areté. Revista de Filosofía, vol. VI, no. 2, 1994, pp. 207-227. 
bosquejado por el procedimiento husserliano de la Quinta Meditación: la alteridad. humana en su diferencia y en su comunidad conmigo aparece originalmente sólo tras haberme reducido a lo más propio, tras sumergirme en el fondo de mí mismo.

Weil observa que el problema de la diversidad de la experiencia comporta diversos aspectos y se reproduce de manera análoga en múltiples áreas. En primer lugar, no se trata sólo del problema gnoseológico de la verdad, como en el caso del "cambio de lecturas" antes mencionado, sino también del problema ético del valor, como en el caso de determinar "si aquel que al ver un bien lee [la necesidad de respetar la propiedad de otra persona], lee mejor que aquel que lee en tal apariencia todos los deseos que podría satisfacer robándolo". ${ }^{37}$ En segundo lugar, este doble aspecto del problema se multiplica de diversos modos, en cuanto la diversidad de lecturas puede darse no solamente entre el yo lector y otro lector coexistentes, sino entre mi experiencia presente y mi experiencia pasada: "Es necesario que yo esté de acuerdo con el otro y con mi yo pasado, mi yo por venir"38 _escribe Weil en sus cuadernos. Por otra parte, la subjetividad lectora puede tener un carácter colectivo, de modo que las diferencias pueden ser entre comunidades humanas contemporáneas (como por ejemplo las diferencias interculturales que han sido tema de la antropología) o entre diferentes épocas del desarrollo de una misma comunidad, lo cual nos enfrenta al problema de la historia: "coordinación [de lecturas] en el tiempo y con las lecturas de los otros. Coordinación entre las lecturas simultáneas y sucesivas". ${ }^{39}$ En el caso de Husserl, se verifica paralelamente que el problema de la diversidad del sentido, partiendo del núcleo primario de la alteridad del otro hombre (en cuanto que "lo primero ajeno en sí -lo primero 'no-yo'- es el otro yo"), ${ }^{40}$ se reproduce también en múltiples direcciones. El problema se extiende, por ejemplo, a la diferencia entre mi experiencia presente y mi experiencia pasada, ya que una vivencia orientada a mi pasado apunta hacia una trascendencia semejante a la de la vivencia presente en que se me aparece otro ser $^{41}$ — una trascendencia semejante, aunque no tan radical como esta última. Por otro lado, Husserl observa también que la sociabilidad humana se articula en comunidades diferenciadas con su entorno cultural propio, "personalidades de orden superior" entre las cuales vuelve a plantearse el

37 S. Weil, "Essai sur la notion de lecture", p. 18, "Por otra parte -continúa-, el problema del valor planteado en torno a esta noción de lectura tiene relación tanto con lo verdadero como con lo bello y el bien, sin que sea posible separar estos términos" (p. 19).

38 S. Weil, Oeuvres complètes VI 2, Gallimard, París, 1997, p. 90. Las cursivas son nuestras.

39 Ibid., p. 90.

40 E. Husserl, Meditaciones cartesianas, op. cit., p. 169.

41 Ibid., p. 179. 
problema de la mutua comunicación y comprensión, no sólo en el "horizonte de simultaneidad" sino también en el "horizonte histórico de sucesión". Todo hombre se mueve en el entorno social y cultural del que proviene y del que ha heredado una tradición con una "comprensión profunda" de su mundo que originariamente "sólo á él le es posible y que está vedada a un hombre de otra comunidad que entre en relación con aquélla". 42 "Yo y mi cultura - continúa diciendo más adelante- somos lo primordial, frente a toda cultura 'ajena'. Para mí y para quienes comparten mi cultura, aquélla es sólo accesible en una especie de experiencia del otro." 43

Es notable que en párrafos recién citados Husserl sugiere que la extrañeza de una comunidad y de los sujetos que pertenecen a ella remite al hecho de su historicidad, esto es, al hecho de ser portadores de una tradición. Klaus Held ha sostenido que es, en efecto, la "generatividad" entendida como la tradicionalidad de la cadena de generaciones de mi mundo familiar, remontándose a la oscuridad mítica, la que constituye el núcleo de extrañeza imposible de reducir, resistente a cualquier apropiación comprensiva por otros, únicamente heredable. ${ }^{44}$ Del mismo modo que cada comunidad intersubjetiva tiene su historia particular con su tradicionalidad y sus "habitualidades sociales", cada ego tiene también su historia en la que "actos habituales de su yo pasado han instituido las habitualidades individuales que constituyen las propiedades permanentes de su yo presente y lo determinan actualmente, ${ }^{45}$ de modo que esta sedimentación particular que se da en cada caso y que orienta la experiencia presente establece diferencias entersubjetivas difíciles de salvar tanto entre comunidades como entre individuos.

Ahora bien, el dato de la diversidad de la experiencia humana del sentido no es abordado ni por Weil ni por Husserl con una actitud de mera constatación resignada como la que podría dar pie a una posición relativista, sino que es vista desde el principio como un problema al que intentarán dar respuesta de varias formas. ${ }^{46}$ En el caso de Husserl, el relativismo parece

42 Ibid., p. 200.

43 Ibid., p. 202.

44 K. Held, "Heimwelt, Fremdwelt, die eine Welt". El fundamento de esta inaccesibilidad por principio, de este abismo de la comprensión es entonces, en la visión de este autor, cariz biológico-generativo. (Cit. por Dieter Lohmar, "La experiencia de lo extraño. Análisis fenomenológico sobre el modo de experiencia de la extrañeza de culturas extrañas", trad. de Graciela R. de Walton y Roberto J. Walton, en Escritos de Filosofía, año XV, no. 29-30, enero-diciembre 1996, p. 38.

45 Roberto Walton, "Husserl y el horizonte de la historia", en Husserl. Mundo, conciencia y temporalidad, Almagesto, Buenos Aires, 1993.

46 Weil dejó clara constancia de esta voluntad de superación del problema en párrafos como el que sigue: "Todos los pensamientos que circulan en un sociedad, cualquiera que sea, 
ser superado, en principio, mediante la determinación de un a priori de la historia y un a priori del mundo de la vida, es decir, la tesis de que "una estructura formal-general del mundo de la vida se presenta en medio de todas las relatividades, [...] [una] forma [que] ya no es relativa sino accesible a todos y determinable de una vez y para siempre como incondicionalmente válida" ${ }^{47}$ Entre estas características constantes del mundo de la vida podrían enumerarse el hecho de estar "pre-dado", el tratarse de un mundo de hombres que vive en comunidad habitando un mundo circundante común, el exhibir un horizonte histórico, los cambios de validez (percepciones reales tornadas aparentes), los fenómenos de cinestesia, la espacio-temporalidad. Pero, como observa R. Rizo-Patrón, la verdadera estructura apriórica del mundo de la vida parece consistir para Husserl en la correlación entre conciencia de mundo y mundo, característica de la intencionalidad, y es a partir de ella que este a priori debe investigarse. Así, analizando esta experiencia trascendental podrían explicitarse tres estructuras esenciales que le son inherentes: la intencionalidad de horizonte (articulada en un horizonte interno, uno externo y el mundo como horizonte de horizontes), la temporalidad (impresiones originarias, retenciones y protenciones; sedimentaciones que orientan la experiencia futura, habitualidades que conforman estilos personales) y la intersubjetividad. ${ }^{48}$ Estas tres estructuras concurren en el concepto husserliano de historicidad primordial, de modo que la historicidad misma pasa a ser considerada como un a priori de la experiencia. En cuanto al a priori de la historicidad, éste estaría dado por el movimiento de sedimentación, reactivación y transformación de sentidos.

Acerca de estas investigaciones de Husserl pueden suscitarse varios interrogantes. Es posible preguntarse, por un lado, como lo hace R. Rizo-Patrón, si la objeción de Husserl contra el relativismo historicista no podría usarse - contra sus mismas tesis en cuanto ha otorgado un carácter apriórico a la historicidad, cayendo entonces el propio lenguaje fenomenológico en la

están influidos por la moral particular del grupo que la domina. [...] Una vez reconocido, se puede reaccionar de muchas maneras, según la profundidad de la inquietud moral. Se lo puede reconocer para los otros e ignorarlo para sí mismo. Esto significa que sencillamente se admite como absoluta moral [relativa] del grupo que se forma parte. [...] O bien se puede tener conciencia de la miserable flaqueza de todo espíritu humano. Entonces sobreviene la angustia. Algunos, para escapar de la angustia, aceptan que las palabras "bien" y "mal" pierdan todo significado. [...] Otros buscan ansiosa, desesperadamente, un camino para salir del terreno de las morales relativas" (S. Weil, "Fragmentos, Londres 1942", en Opresión y libertad, Sudamericana, Buenos Aires, 1957, p 184).

47 R. Walton, "Husserl y el horizonte de la historia", op. cit., p. 160.

48 Rosemary Rizo-Patrón, "Ciencia, progreso y exilio del sujeto. En torno a ciertos mitos modernos y post-modernos", Areté. Revista de Filosofia, vol. VI, no. 2, 1994, pp. 295. 
relatividad histórica y quedando inhabilitado para realizar su pretensión de investigar esencias atemporales. En otra dirección es posible también cuestionar, junto con D. Carr, la "efectividad" de este a priori, es decir, preguntarse si esta estructura común general del modo de darse del mundo, aun si hubiera sido correctamente determinada por Husserl, deja efectivamente atrás el problema del conflicto derivado de la diversidad histórica y cultural de mundos, si permite una mediación y comprensión efectivas entre ellos $^{49}$ o es demasiado general o formal como para hacerlo. Se trata de una crítica cercana en algún sentido a la que, en el contexto de una discusión ya no de carácter gnoseológico sino ético, Peter Winch formula a la tesis de MacIntyre de que mientras que existe una pluralidad de moralidades existe a la vez algo invariante y común a toda sociedad, y esto es, precisamente, el que todas poseen una moralidad suficientemente inteligible y fundamentada para sus propios miembros, que hace posible la satisfacción de sus necesidades particulares mediante su cumplimiento. Frente a esto, Winch observa que "como otras muchas posturas filosóficas, ésta puede sostenerse como último bastión en la medida en que uno está dispuesto a vaciarla de contenido", 50 dejando por tanto intacto el problema.

Los intentos de Weil en sus últimos escritos por hallar una "geometría de la experiencia" que permita pensar una "mediación" entre lecturas inconmensurables se halla probablemente expuesta a objeciones semejantes. Mientras que efectivamente nos provee de un modelo para conciliar la diversidad de la experiencia humana con su aspiración racional de verdad y bien, probablemente no llega a ser suficientemente concreta como para mostrar en qué consiste la posibilidad efectiva de la comunicación y comprensión entre extraños, no llega a precisar en qué se fundaría la comunidad de los diferentes. Repasemos los argumentos de Weil.

Weil se refirió al problema de la inconmensurabilidad de la experiencia de dos modos diferentes, si bien correlativos. Hasta ahora calificamos con la condición de inconmensurabilidad a la relación entre las diversas lecturas. La imposibilidad de evaluar o de dar sentido de su diversidad significa la inexistencia de un criterio, de un sentido que esté en relación con esta diversidad. En la cuestión de la inconmensurabilidad entre las diversas lecturas está coimplicada, entonces, la cuestión de la inconmensurabilidad entre la diversidad de lecturas y la unidad del criterio o del sentido, y Weil creyó más fácil hallar una solución a la primer cuestión traduciéndola en los términos de la segunda. Ahora bien, que existe una inconmensurabilidad, una diferencia absoluta entre la diversidad propia de la experiencia humana y

49 David Carr, Phenomenology and the Problem of History, cit. por R. Walton, op. cit., p. 161.

50 Peter Winch, "Naturaleza humana", en Comprender una sociedad primitiva, Paidós, Barcelona, 1994, p. 165. 
la unidad del sentido, la verdad o el bien, significa que esta unidad sólo puede ser definida negativamente como lo diferente de o el más allá del ámbito de la experiencia posible. En tanto participantes de la experiencia humana, una experiencia en que el sentido es esencialmente relativo, la verdad y el bien únicos y absolutos tienen para nosotros en primer lugar la signficación del vacío, de la ausencia absoluta del sentido, el sentido único es el sin sentido absoluto: Weil habla así del vacío, la no-lectura, el silencio, lo "sin-nombre-ni-forma", lo sobrenatural.

Según expresa Weil en su escrito "A propósito de la doctrina pitagórica" los antiguos pitagóricos emplearon el término alogos (que Weil relaciona con la "inconmesurabilidad") primeramente para calificar la relación entre la multiplicidad y la unidad y luego para referirse a la relación entre múltiples magnitudes. "Si se consideran los números enteros - escribe allí Weilse observa que son de dos tipos; aquellos que están ligados a la unidad por un medio proporcional, $4,9,16$, por una parte, y por otra parte todos los demás. [...] Nosotros [los hombres] nos asemejamos a los segundos."51 Es decir: los números cuadrados tienen en su raíz un medio proporcional entre sí mismos y la unidad. 1 es a 3 como 3 es a 9: 3 es entonces el medio proporcional entre 1 y 9 . Los números no cuadrados carecen de esta relación con la unidad en el ámbito de los números enteros. " ¿Es a fuerza de buscar intensamente una mediación para estos números miserables que los griegos han descubierto la geometría?" — se pregunta Weil recordando la versión de Filolao del origen divino de la geometría. En efecto, el problema de encontrar el medio proporcional entre inconmensurables, imposible de solucionar en la aritmética de los números enteros, encuentra su solución al traducir el problema en términos geométricos (a saber, construir un triángulo rectángulo estando dados la hipotenusa y el pie de la altura). Una "geometría de la experiencia humana" significaría entonces la posibilidad de concebir una relación de la diversidad de la experiencia con la unidad del más allá de la experiencia, el bien y la verdad, lo que significaría a la vez una coordinación -en el sentido antiguo de "armonía" o "amistad" - de las diversas lecturas entre sí. La armonía que define a la amistad era entre los pitagóricos "el pensamiento común de quienes piensan separados". 52

Escribe Peter Winch:

Cuando existe este tipo de inconmensurabilidad [entre aspectos incompatibles de la naturaleza humana, ninguno de los cuales puede ser negado], nuestra dificultad es la de encontrar alguna perspectiva desde la cual todos los fenómenos

$51 \mathrm{~S}$. Weil, "À propos de la théorie pythagoricienne", en Intuitions prechrétiennes, Librairie Artème Fayard, Paris, 1985, p. 121.

52 . Cfr. ibid., pp. 127 y ss. 
bajo consideración puedan ser vistos juntos como sistemáticamente interconectados. Ésta es parte de la razón por la que Weil enfatiza la importancia de la geometría en tales casos. Sólo una forma geométrica de representación puede tratar con inconmensurables. ${ }^{53}$

¿En qué consistiría tal representación geométrica de la experiencia? Weil insiste en sus Cuadernos en la necesidad de construir "una representación del mundo que incluya un vacío". ${ }^{54}$ La expresión es paradójica: ya observamos que el vacío es justamente el reverso del mundo y la experiencia caracterizados por lo diverso y lo relativo. ¿Cómo estaría "incluido" en el mundo? La idea de Weil es que esta representación desplazaría el centro de perspectiva desde el cual se organiza la experiencia hacia un punto exterior a ella, de ese modo el más allá de la experiencia estaría "presente" en la experiencia no como una parte de ella, sino como su orientación. Es necesario "realizar una operación análoga a la que nos permite percibir el espacio rebajando a su rango las ilusiones de la perspectiva. Es necesario reconocer que nada dentro del mundo es el centro del mundo, que el centro del mundo está fuera del mundo". 55

Lo sobrenatural no aparece más que a través de lo natural, la unidad a través de la diversidad.

El análisis de la percepción de un cubo provee a este respecto de una metáfora perfecta. [...] No hay ningún punto de vista desde donde la caja tenga la apariencia de un cubo; no se ven nunca más que algunas caras, los ángulos no parecen rectos, los lados no parecen iguales. Nadie ha visto nunca ni nadie verá nunca un cubo. Nadie ha tocado ni tocará jamás un cubo, por razones análogas. [Sólo tocará aristas, superficies más o menos planas, vértices, etc.] Si damos la vuelta alrededor de la caja se engendra una variedad infinita de formas aparentes. La forma cúbica no es ninguna de ellas. Es otra que todas ellas exterior a todas ellas, trascendente a su dominio. Al mismo tiempo constituye su unidad. Constituye también su verdad. ${ }^{56}$

El modo en que diversas experiencias parciales se integran para configurar la experiencia de un objeto es un modelo del modo en que la experiencia en general, múltiple y relativa, puede integrarse en un sentido universal. Este último no aparece por sí mismo, como tampoco lo hace nunca el cubo como tal, sino que sólo es leído en o a través de la misma multiplicidad y relatividad de la experiencia.

53 P. Winch, op. cit., p. 156.

54 Cit. por P. Winch, op. cit., p. 12.

55 S. Weil, op. cit., p. 137.

56 Ibid., p. 169. 
Nuestra experiencia humana es intrínsecamente diversa y relativa, lo uno y absoluto está definitivamente excluido de ella. El único modo en que podría estar "presente entre nosotros" sería a través de algo del ámbito de lo diverso y relativo investido de un exceso de sentido, una experiencia indirecta de este más allá de lo experimentable. Esta experiencia o elemento de la experiencia es el equivalente del término mediador entre números inconmensurables provisto por la geometría, por lo que Weil se refiere a él como al metaxú. El término mediador constituye un logos alogos, algo que aparece como "un escándalo, un absurdo, una cosa contra la naturaleza", 57 porque encarna una contradicción flagrante: es a la vez arbitrario y necesario, pertenece al dominio de lo diverso y relativo pero manifiesta algo único y absoluto.

Podemos preguntarnos en qué sentido esta figura de la mediación con la que Weil responde al problema de la inconmesurabilidad de lo múltiple y lo uno, lo relativo y lo absoluto, provee a la vez la posibilidad de coordinar o armonizar las diversas lecturas inconmensurables entre sí, ya que, como se vio, ambas dimensiones del problema de la inconmensurabilidad se coimplican. Si bien esto no constituye un "criterio" para "medir" las lecturas entre sí, la figura weiliana de la mediación provee un particular modo de coordinar las lecturas inconmensurables manteniendo lo que tienen de diverso y particular. Ya que el planteamiento del problema de la diversidad inconmensurable de las lecturas conlleva implícitamente la referencia a la unidad del más allá de la lectura, podríamos representarnos gráficamente las diversas lecturas como diversos segmentos que confluyen en un mismo punto-eje, el "centro vacío" de Weil. Tendríamos entonces la posibilidad de marcar en cada uno de los diversos segmentos un punto a igual distancia del centro (la conjunción de los puntos conformaría un círculo); es decir: deberían existir ciertas lecturas ("mediadoras") que conservando su diversidad (su pertenencia a segmentos diferentes) son igualmente valiosas o están igualmente cercanas de la verdad (el centro vacío). Del mismo modo, según una imagen usada por Weil, dos personas encerradas en celdas cercanas pueden tener desde su ventana acceso a una perspectiva muy distinta del mismo objeto. Esta perspectiva limitada y relativa puede ser para cada uno el único modo en que tendrá acceso a la verdad del objeto, y ambas son, en su diferencia, valiosas y verdaderas. Weil sugerirá que, ya que no es posible acceder a la verdad sin la mediación de una "ventana", es decir, de una perspectiva, es posible beneficiarse del cambio de perspectiva, lo cual explica el gran interés que mostró en sus últimos años por el folklore, religiones, mitos y en general tradiciones culturales diversas, lejanas en el tiempo y en el espacio (orientales, americanas, etcétera).

57 S. Weil, "À propos de la doctrine pythagoricienne", op. cit., p. 124. 
Esta formulación excluye, evidentemente, cualquier idea de progreso o de direccionalidad histórica. Si en la visión cristiana, por ejemplo, la encarnación es el hito único en que la verdad aparece en forma humana e histórica imprimiendo al tiempo un sentido irreversible en pos de un fin de la historia (parousia), la visión de Weil implica que Cristo (quien es para ella la imagen del metaxú) es idéntico a todas las apariciones de verdad en todas las culturas y todas las épocas. Una vez abandonada toda idea de teología histórica es posible reconocer que el mismo sentido revelado por los símbolos de una religión como la cristiana, en tanto sea verdadero, debe haber tenido posibilidades de expresión en una gran diversidad de otras religiones y mitos, incluso pre-cristianos y paganos. Los muy diferentes mitos e historias acerca de la creación, por ejemplo, "son diversos reflejos de una verdad única intraducible en palabras humanas. Se la puede presentir a través de uno de esos reflejos. Se la presiente mejor a través de varios". ${ }^{58}$ Observamos que Weil está de este modo afirmando dos cosas simultáneamente: ninguna de estas expresiones se identifica con la verdad, la cual propiamente permanece siempre "intraducible" más allá de la experiencia humana, pero a la vez no tenemos atisbos de la verdad más que por medio. de alguna de estas expresiones, cuan diversas y relativas sean. Cualquier doctrina, aun si fuera la más perfecta, debería ser vista como un "velo" o "reflejo" —escribe Weil tomando una metáfora de los místicos: no como si fuera la verdad, sino como algo detrás de lo cual se encuentra la verdad. ${ }^{59}$

La concepción weiliana de la trascendencia de la verdad respecto de la experiencia es la que funda a la vez la tolerancia y el interés de Weil frente a la diversidad cultural humana y el rechazo tanto de la escatología tradicional cristiana como de su secularización en las filosofías de la historia. El dogma del progreso

deshonra al bien al hacerlo asunto de este mundo; [. . . L La superstición moderna del progreso es un subproducto de la mentira por la cual se hizo del cristianismo la religión romana oficial; está ligado a la destrucción de los tesoros espirituales de los países conquistados por Roma, a la ocultación de la perfecta continuidad de estos tesoros y el cristianismo, a una concepción histórica de la redención que ha hecho de ella una operación temporal y no eterna. Más tarde la idea de progreso se hizo laica; ahora es el veneno de nuestra época. ${ }^{60}$

58 Ibid., p. 49, Wittgenstein otorgaba el mismo valor alegórico de señalar algo más allá de la experiencia al sentimiento de asombro ante la existencia del mundo que se expresa en lenguaje religioso como "Dios creó al mundo".

59 Ibid., p. 28.

60 S. Weil, Raíces del existir, Sudamericana, Buenos Aires, 1954, pp. 228-229. 
Las reflexiones de Weil sobre la diversidad histórica y cultural de las instituciones políticas pueden servir para elucidar aún más la cuestión de la relación entre diversidad y unidad, relatividad y verdad en la historia.

Las formas y expresiones del consentimiento [i.e., de la justicia, o el bien] varían mucho en diferentes tradiciones y medios. Así una sociedad de hombres más libres de lo que somos nosotros, si es muy diferente de la nuestra, puede parecernos despótica en nuestra ignorancia. [...] Un rey puede ser legítimo. Así también lo puede ser una dirección parlamentaria de gobierno. [...] [Las instituciones políticas] son análogas a las cartas de amor, el intercambio de anillos y otras prendas entre amantes. En algunos círculos una mujer no se consideraría a sí misma como realmente casada si no usara anillo de oro. Por supuesto el lazo conyugal no consiste en el anillo. Pero igualmente es necesario para una mujer que siente de ese modo usar el anillo. ${ }^{61}$

Los mismos criterios con que Weil juzga la diversidad de religiones, costumbres sociales y sistemas políticos pueden aplicarse a la diversidad de filosefías auténticas: negación de todo progreso, trascendencia de la verdad y simultánea valoración de la necesaria diversidad de expresiones de esta verdad: "Siempre se ha filosofado, y existe una tradición filosófica que es tan antigua probablemente como la humanidad y que [...] durará tanto como ella. [...] De que ella sea siempre la misma, no se sigue que sea útil repetirla; al contrario, en cada época, en cada país, es deseable que sea transpuesta." ${ }^{2}$ La trascedencia absoluta de la verdad respecto del pensamiento implica a la vez que ninguna filosofía puede expresar de manera absoluta la verdad, pero la verdad no aparece esbozada para nosotros más que epocal y culturalmente, al ser transpuesta en una u otra filosofía. Al pensamiento se le exige, entonces, a la vez, el máximo esfuerzo de búsqueda y precisión, puesto que la verdad no tendrá expresión fuera de él, pero a la vez la reserva de no creer nunca haberse adueñado de la verdad: "Considero que cierta suspensión del juicio con respecto a todos los pensamientos, cualesquiera que sean, sin excepción, constituye la virtud de la humildad en el plano de la inteligencia." 63

${ }^{61} \mathrm{~S}$. Weil, "Luttons-nous pour la justice?", en Ecrits de Londres, cit. por P. Winch, op. cit., p. 186.

62 S. Weil, Oeuvres complètes VI 1, op. cit., p. 175. Un concepto similar de unidad a través de la diversidad aparece en la caracterización heideggeriana de la filosofía: "La filosofía, desde Aristóteles a Nietzsche, precisamente sobre la base de estos cambios y a través de ellos, sigue siendo la misma. Pues las transformaciones son la garantía para el parentezco en lo mismo (Das Selbe)" (M. Heidegger, ¿Qué es eso de filosofía, trad. de A. Carpio, Sur, Buenos Aires, 1960, p. 35).

63 S. Weil, Carta a un religioso, trad. de M.E. Valentié, Sudamericana, Buenos Aires, 1954, p. 9. 
El concepto de una tradición filosófica verdadera "eterna de derecho y antigua de hecho" acompañó a Weil desde sus primeros escritos, en los que se percibía la influencia de su maestro. El que la "verdadera filosofía", aquella que enraizaría en lo más concreto de la existencia, ya haya sido pronunciada por los grandes pensadores del pasado y sólo necesite ser meditada una y otra vez sin cesar, era una idea que Alain había hecho propia al referirse en diversas ocasiones a la véritable philosophie, la grande philosophie o la philosophie commune. Esta idea era solidaria del antihistoricismo alainiano y de su noción de étages, por la que ninguna forma histórica aparece definitivamente superada (contrapuesta a la de étapes, propia de León Brunschvicg, también profesor de Weil y director de su Memoria de Licenciatura sobre Descartes). S. Pétrement se ha referido a este punto al analizar las relaciones entre el pensamiento "percepcionista" de Alain y Lagneau y la fenomenología alemana, dándonos a la vez una clave del contraste que en este sentido podría establecerse entre las observaciones de Weil que venimos considerando y una visión como la de Husserl:

para Husserl los filósofos del pasado, si bien algunos de ellos han entrevisto verdades importantes, no han acertado a fundar sobre una base sólida el conjunto de verdades apodícticas que debe constituir la filosofia; él pensaba que tal conjunto de verdades podría finalmente ser establecido gracias al método fenomenológico; en tanto que para Lagneau y Alain [al igual que para Weil], la verdad filosófica ha sido conocida por los más grandes filósofos del pasado en igual medida en que podrá ser posible siempre que sea conocida. ${ }^{64}$

En efecto, Husserl otorga un lugar privilegiado a la fenomenología en la historia del pensamiento al distinguir tres niveles en la historicidad: el de las comunidades prefilosóficas, el de la cultura filosófica y científica y el de la transformación de la filosofía en fenomenología, con lo cual los niveles anteriores alcanzan la plenitud de su sentido. ${ }^{65}$ Por medio de una "consideración interior" de la historia que va más allá de lo fáctico hacia la consideración de los procesos históricos de institución, sedimentación, reactivación y transformación de los sentidos, Husserl descubre en la historia universal un movimiento teleológico que se instituye en Grecia entre los siglos vi y vi a.C. y que apunta hacia ideales -más precisamente, hacia una "idea"- de racionalidad y libertad. Este comienzo es un "comienzo teleológico" en cuanto "esta institución originaria (Urstifung) encierra el proyecto de una institución final (Endstifung) en la que se revela plenamente

64 Simone Pétrement, "Remarques sur Lagneau, Alain et la philosophie allemande contemporaine", Revue de métaphysique et de morale, no. 1, 1970, pp. 292-300.

65 Nos basamos en este punto en los análisis de R.J. Walton en "Husserl y el horizonte de la historia", en Husserl. Mundo, conciencia y temporalidad, op. cit., pp. 142 ss. 
a través de una toma de conciencia de sí (Selbstbesinnung) con respecto a lo que estaba implícito en ella". ${ }^{66}$ Esta toma de conciencia de sí en la que el sentido latente se consuma es la filosofía fenomenológica, pero no se trata en este caso de un remedo de la filosofía hegeliana de la historia. La idea-meta se manifiesta en la historia, y en este sentido puede recordar al movimiento dialéctico del espíritu hegeliano, pero de modo aún más similar a Kant, es una idea que conserva a la vez su trascendencia, cuya realización Husserl reconoce que está siempre, esencialmente, "en camino": "una idea que reside en el infinito, y que en el factum se encuentra necesariamente en camino". ${ }^{67}$ La concepción weiliana de la historia coincide con la de Husserl en la medida en que la verdad conserva su trascendencia respecto de la historia pero a la vez se manifiesta en ella. Sin embargo, mientras que Weil se opone a reconocer en la historia un progreso orientado en una dirección única, Husserl observa un único movimiento progresivo, aun si este proceso se extendiera ad infinitum acercándose de modo asintótico al ideal que lo orienta. La concepción de Weil se acercaría más, posiblemente, a la de una "red" o "cadena de mundos particulares" y de "líneas divergentes de desarrollo histórico" que tienen cada una en sí misma una relación particular con la verdad. Estos últimos son los conceptos utilizados por B. Waldenfels como alternativa a los recursos de una estructura universal a priori y de una teleología racional histórica mediante los cuales Husserl pretende trascender las diferencias entre comunidades y mundos de la vida extraños cultural o históricamente. ${ }^{68}$

Tanto las estructuras aprióricas postuladas por Husserl como el modelo trans-histórico y trans-cultural de la mediación trazado por Weil son indicaciones útiles para investigar la posibilidad de conciliar la diversidad de la experiencia humana con la paralela aspiración humana de verdad, esto es, de "dar sentido" de esta diversidad. Sin embargo, como observábamos más arriba, pueden resultar demasiado generales a la hora de enfrentar teóricamente los problemas concretos, por ejemplo, de la comprensión de una cultura extraña, lejana histórica o geográficamente. Ahora bien, en el caso de ambos filósofos hallamos indicaciones para investigar el sentido concreto de estos modelos universales de comprensión en dirección a la cuestión de la corporalidad. Ya que para investigar el aparecer originario de la alteridad es necesario remontarse a la corporalidad, tal como lo hace Husserl en la Quinta Meditación Cartesiana será necesario volver a la corporalidad para vislumbrar lo que sea que pueda trascender $\longrightarrow$ hacer de base común - a esta diversidad.

66 R. Walton, op. cit., p. 144.

67 Hua. VI, 274, cit. por R. Walton, op. cit., p. 147.

${ }^{68}$ Cfr. R. Walton, op. cit., p. 149 ss. 
En el parágrafo 44 de la Quinta Meditación Husserl observa que tras operar una reducción de la experiencia trascendental a la esfera de lo propio - primer paso en esta investigación de la experiencia de lo otro- subsiste un estrato caracterizable como "una naturaleza mía propia", distinta de la naturaleza del físico: mi cuerpo vivo (Leib), cuyas cinestesias tienen la forma del "yo hago" y están sometidas a mi "yo puedo". Mi cuerpo es el habitante y el centro de orientación de un "mundo primordial" o "naturaleza primordial" que aparece en mi mónada como una "trascendencia inmanente". El paso por el cual en esta trascendencia inmanente el otro llegará a constituirse en una verdadera trascendencia - a partir de la cual podrá hablarse luego de una comunidad intermonádica y un correlativo mundo objetivo- será un tipo peculiar de apresentación o apercepción analógica ("parificación") en la que se transifere o "contagia" el sentido de mi cuerpo vivo a otro cuerpo que, a diferencia de cualquier objeto, presenta dos características. Por un lado, observa Husserl, si el sentido transferido por analogía a un objeto remite a una protofundación (en la que por primera vez constituí un objeto de sentido semejante), en este caso la protofundación "es de continuo aquí algo presente de modo vivo; [.. .] permanece constantemente realizándose viva". ${ }^{69}$ En segundo lugar, como ya observamos más arriba al hablar de una "accesibilidad de lo no-accesible" originalmente, la apresentación del otro no puede nunca tornarse plena presencia, auténtica percepción: "nada del sentido recibido de específica corporalidad viva puede realizarse originalmente en mi esfera primordial". ${ }^{70}$ La singular opacidad que constituye la experiencia del otro como otro se funda, resume Husserl, en la "conducta" corporal que exhibe, siendo esta "conducta" un índice ambiguo, en que lo físico se entreteje con lo psíquico, un indicio que señala hacia algo más que nunca se me da originariamente. ${ }^{71}$

En la teoría de la experiencia como lectura de significaciones que Weil desarrolla en la madurez de su pensamiento la filósofa observa, de manera similar a Husserl, una diferencia esencial entre la constitución del sentido de un objeto y el sentido de la alteridad humana (distinta de la de cualquier objeto en tanto "un hombre situado a diez pasos de mí es algo separado de mí por una distancia (diez pasos) pero también es otra perspectiva bajo la cual aparecen todas las cosas"). ${ }^{72} \mathrm{Al}$ igual que Husserl, Weil hace radicar esta diferencia justamente en la conducta corporal, si bien, en este caso

69 E. Husserl, Meditaciones cartesianas, op. cit., §51, p. 175.

70 Ibid., p. 177.

71 Ibid. §52. Puedo acceder sólo parcialmente a los contenidos psíquicos del otro (alegría, ira, etc.), mediante una endopatía basada en su comportamiento exterior que comprendo a partir de mi propio comportamiento en circunstancias afines $(\S 54)$.

72 S. Weil, Oeuvres complètes VI 1, op. cit., p. 295. 
se trata de la propia. De modo más similar a Merleau-Ponty, Weil considera que el sentido leído se constituye mediante el aprendizaje habitual de patrones de movimiento corporal - de modo primario respecto de toda operación intelectual o lingüística-, de modo que la constitución de la alteridad humana se caracterizará por una alteración particular de estas conductas dadoras de sentido:

Cualquiera que esté en mi cercanía ejerce cierto poder sobre nosotros por su misma presencia [...], el poder de interrumpir, réprimir, modificar cada movimiento que mi cuerpo esboza. Si damos un paso al costado, frente a un paseante en la calle, no es lo mismo que si lo hacemos para evitar una valla; cuando estamos solos en nuestro cuarto, nos levantamos, caminamos, nos sentamos de nuevo de manera notablemente diferente que cuando tenemos un visitante. ${ }^{73}$

Como expresa Peter Winch, "la danza que constituye nuestra percepción del mundo sigue distintos pasos aquí". ${ }^{74}$

Ahora bien, si es en esta esfera primaria de nuestra corporalidad donde, en la visión de Husserl como en la de Weil, se funda la constitución de la alteridad, es a ella que se deberá retornar para investigar la superación del problema resultante de la diversidad del sentido. Husserl se muestra consciente de la variedad de aspectos y la radicalidad de este problema en reiteradas ocasiones a lo largo de la Quinta Meditación. Lo hace primeramente, como vimos, al reconocer una inaccesibilidad originaria en la conducta del otro: "¿Acaso no están ambas esferas primordiales [...] separadas por un abismo que yo no puedo realmente cruzar [...]?"75 Lo hace luego al referirse a las "anomalías" (casos de sistemas perceptivos que "se salen de la regla": personas ciegas, sordas, etc.) y también a la animalidad. ¿Cómo puede el mundo conservar su carácter de uno y objetivo si este carácter se constituye intersubjetivamentte a partir de la identidad de los sistemas fenoménicos de sus habitantes, y sus sistemas fenoménicos pueden ser a tal punto diversos como en estos casos? ${ }^{76}$ La cuestión de la diversificación del sentido se cuela luego una vez más en su meditación en relación con la diversidad cultural, cuando al arribar al estudio de la constitución de "personalidades de orden superior" (familias, comunidades, naciones, estados, etc.) encuentra que a éstas corresponden "entornos culturales" muy distintos que comportan cada uno en sí mismo cierta "objetividad", si bien ésta es "limitada" en cuanto su accesibilidad no es incondicionada

73 S. Weil, S. Weil: An Anthology, Virago, Londres, 1986, p. 187, cit. por P. Winch, op. cit., p. 105.

74 P. Winch, op. cit., p. 105.

75 E. Husserl, Meditaciones cartesianas, op. cit., p. 186.

76 Ibid., §55, p. 191. 
sino restringida - al menos en principio - a los miembros de la comunidad. Incluso puede darse que

los hombres de uno y el mismo mundo vivan en muy tenue comunidad cultural, o en ninguna en absoluto, y que, de acuerdo con ello, constituyan entornos culturales diversos como mundos cotidiantos concretos en que viven en acción y pasión las comunidades relativa o absolutamente separadas. ${ }^{77}$

Finalmente, la cuestión de los límites de la diversidad del sentido es abordada explícitamente por Husserl al considerar, remitiéndose a Leibniz, la posibilidad de una "pluralidad incomposible" de grupos de mónadas y mundos: " $i E s$ concebible [...] que coexistan separadas, o sea no estando en comunidad alguna unas con otras, varias pluralidades de mónadas, cada una de las cuales, pues, constituye un mundo propio?"78 Esta posibilidad abstracta será descartada como absurda en cuanto por diversas que sean estas intersubjetividades "se hallan en comunidad necesaria conmigo como mónada originaria constituyente respecto de ellas". La conclusión de Husserl tras considerar las distintas apariciones del problema de la diversidad del sentido parece ser resumida entonces en la afirmación de que "sólo puede haber en realidad una única comunidad de mónadas coexistentes; y, en consecuencia, no puede haber más que un único mundo objetivo, un único tiempo objetivo, un solo espacio objetivo, una sóla naturaleza". ${ }^{79}$ ¿Dónde radica la confianza de Husserl en la posibilidad de trascender estas diferencias, una vez que las ha reconocido en su diversidad de manifestaciones y su radicalidad? Tanto la primera comunidad del yo y el tú, la convergencia de sistemas fenoménicos anómalos y aun animales en un mismo mundo, así como la comprensión de comunidades culturalmente diversas a partir de un núcleo de familiaridad remiten en la reflexión de Husserl a un estrato de la experiencia compartido cuyo principal referente es la corporalidad viva en su "soplamiento", "entretejimiento" o "mutuo suscitarse" con la corporalidad extraña. Esta "naturaleza primordial", a la que ya nos referimos, es la primera forma de comunidad a la que remiten todas las otras: "Lo primero constituido en la forma de la comunidad es el carácter común de la naturaleza, que se constituye a la vez que el del cuerpo vivo ajeno y el yo psicofísico ajeno en parificación con el yo psicofísico propio." ${ }^{80}$ No cabe aquí la pregunta, a diferencia de los estratos superiores de la experiencia de un mundo objetivo, de cómo llegaré a aprehender la naturaleza que mi cuerpo habita como la

77 Ibid., p. 200.

78 Ibid., p. 208.

79 Ibid.

${ }^{80}$ E. Husserl, ibid., §55, p. 185 . Las cursivas son nuestras. 
misma que habita el otro, porque en la misma apresentación del otro en mi esfera primordial mediante su conducta corporal, en un solo y mismo movimiento "está ya necesariamente producido el sentido de identidad de 'mi' naturaleza primordial y la otra"," 81 es decir que mi habitación carnal es originariamente co-habitación, y la naturaleza no fue nunca primero "mi" naturaleza, sino que es desde siempre "nuestra" naturaleza.

Es a partir de estas consideraciones de Husserl que Merleau-Ponty va a considerar una dimensión carnal originaria donde yo y otro, sujeto y mundo co-existen entrelazados. Aun si reconocemos hallarnos en cierto nivel de la experiencia "sin ningún terreno común con el otro", donde "la posición del otro con su mundo y la proposición de mí mismo con un mundo constituyen una alternativa", también es necesario que primero "mi experiencia me dé de alguna manera al otro, puesto que de no hacerlo yo no hablaría siquiera de soledad ni podría declarar inaccesible al otro". Se trata menos de analizar cómo es que puede constituirse mi comunidad con el otro a partir de la diferencia, que de "volver a lo social, con lo que estamos en contacto por el solo hecho de que vivimos": "el cuerpo del otro y el mío son un único todo, el anverso y el reverso de un único fenómeno, y la existencia anónima, de la que mi cuerpo es, en cada momento, el vestigio, habita en adelante estos dos cuerpos a la vez" ${ }^{82}$ Reencontrar esta comunidad carnal originaria exigiría remontarse a una "región salvaje de sí mismo", un "ser bruto" o "ser salvaje" como ámbito de la experiencia aún no incluido en la propia cultura ni interpretado por un lenguaje particular. Se trata de repensar originariamente el Lebenswelt bajo la forma de un "mundo salvaje", "un mundo donde la distinción entre lo subjetivo (psíquico) y lo objetivo (en sí) no ha sido hecha aún". ${ }^{83}$ B. Waldenfels vio también en la dilucidación de esta región la posibilidad de fundar la comprensión de otros mundos de la vida sin pasar por alto la radicalidad de su diversidad. ${ }^{84}$

Nos hallamos aquí en una dimensión pre-objetiva, a la que es inherente una cierta opacidad - como la que revisten para nosotros los fenómenos del nacimiento, la sexualidad y la muerte-y es precisamente en medio de y en virtud de esta opacidad que existe este modo primario de comunidad. La existencia carnal es portadora para mí de un "pasado originario" - como el del nacimiento- que me impide ser transparente para mí mismo, y encuentro al otro en esa opacidad compartida con él. Del mismo modo, mi carnalidad señala hacia un "futuro inaccesible" — como el de mi muerte-,

81 Ibid., p. 189.

82 Maurice Merleau-Ponty, Fenomenología de la percepción, op. cit., pp. 365 ss.

83 M. Merleau-Ponty, Notes de cours (1959-1961), Gallimard, París, 1996, p. 77.

84 Por ejemplo, en B. Waldenfels, "Verschränkung von Heimwelt und Fremdwelt", cit. por Dieter Lohmar, op. cit., p. 29. 
y es así que mi vida tiene un sabor social al tiempo que tiene este sabor mortal. ${ }^{85}$ Finalmente, en sus últimos escritos Merleau-Ponty halla una situación modélica del entrelazo carnal en que comulgan lo propio y lo extraño en la sexualidad ${ }^{86}$ Podrían relacionarse estas consideraciones de Merleau-Ponty con lo ya adelantado por Husserl respecto de una proto-intersubjetividad fundada en ciertas habitualidades peculiares que denomina "instintivas". 87 En este nivel, la experiencia del otro se da a partir de impulsos instintivos cuya satisfacción puede resultar en el nacimiento de un nuevo ser. Así la sexualidad, la procreación y el nacimiento son dotados por Husserl de una significación fenomenológico-trascendental, cuyos corolarios ontológicos Merleau-Ponty sólo explicita al observar que en el nivel carnal mi existencia está originariamente mezclada, superpuesta, co-implicada con la de los otros, conformando una especie de magma viviente. ${ }^{88}$

Husserl reconoce aun un sustrato común del mundo a partir del cual puede abrirse la posibilidad de comprensión de mundos extraños en la dimensión de lo "protogenerativo", entendido como una base de necesidades periódicamente recurrentes:

Procurar alimento, cocinar, comer, beber, dormir, son acciones que comprendemos sobre la base de nuestra común constitución corporal. [...] [De este modo] antes de toda comprensión que puedo luego también expresar con mi lenguaje, nos comprendemos ya corporalmente como hombres con otros hombres. ${ }^{89}$

Sin embargo, Merleau-Ponty tiene razones para otorgar en sus análisis un lugar más destacado y diferencial a los fenómenos del nacimiento, la sexualidad, la muerte como fundamentos de una primaria comunidad carnal. Desde una óptica distinta de la fenomenológica, Peter Winch ha llegado a conclusiones similares en su discutido trabajo "Understanding a Primitive Society". Allí sostiene, tras radicalizar el sentido de las diferencias interculturales al punto de que se haya llegado a ver erróneamente en este ensayo un emblema del relativismo cultural, que existen ciertas "nociones delimitadoras" en la vida humana, las cuales Winch hace corresponder con aquellas en las que Vico fundamentó su idea de ley natural y la posibilidad de comprender la historia. Estos rasgos "presentes en la vida de toda sociedad humana conocida, de un modo que nos proporciona una clave donde

85 M. Merleau-Ponty, op. cit., pp. 362, 375.

86 M. Merleau-Ponty, "El entrelazo, el quiasmo", en Lo visible y lo invisible, trad. de J. Escudé, Seix Barral, Barcelona, 1966, p. 179.

87 R. Walton, op. cit., p. 155.

88 Cfr. Merleau-Ponty, Notes de cours au Collège de France 1958-1961, Gallimard, París, 1996, p. 211.

89 Dieter Lohmar, op. cit., p. 29. 
mirar si nos encontramos desorientados acerca del sentido de un sistema de instituciones extraño", son precisamente los del nacimiento, la muerte y las relaciones sexuales. ${ }^{90}$ Es necesario observar que si bien Winch liga estas nociones a una dimensión ética, no intenta por medio de ellas proveèr la base de un criterio moral que sirva para dirimir definitivamente desacuerdos de este tipo. En su ensayo "Human Nature" se ocupó precisamente de desbaratar la legitimidad de la apelación al sustrato de una "naturaleza humana", en discusiones morales. Estas "nociones límite" de la "vida humana", en cambio, constituyen una orientación para la comprensión de una sociedad extraña en cuanto tendrán un lugar central en toda sociedad humana, pero a la manera de un problema que encuentra en cada una un modo propio y diferente de afrontarlo. ¿Cuáles son las razones por las que Winch considera que son estos rasgos los que deben considerarse universales? Su argumento, en los tres casos, apunta a mostrar que, a diferencia de otros acontecimientos o experiencias que son "componentes" particulares de la vida humana, éstos son "modos" propios de la vida, no acontecen dentro de la vida, sino que son los modos en que la vidad humana misma acontece. Teniendo en cuenta que la vida humana no es mera "vida animada" sino por esencia vida que se ocupa de "dar sentido" a acciones y acontecimientos, lo cual implica que las cuestiones acerca de la manera correcta de vivir o de qué cosas son más importantes en la vida no son ajenas a ningún humano, se hace evidente que las tres "nociones límite" exceden lo biológico y tienen por sí mismas una relevancia ética. La muerte, por ejemplo, en cuanto no señala un futuro acontecimiento en mi vida, sino el cese mismo de mi vida, de mi mundo e incluso de mi capacidad de obrar bien o mal, hace que

mi propio concepto de lo que es ser capaz de obrar bien o mal esté profundamente ligado al concepto de mi vida que va a parar a la muerte. Si la ética es una preocupación por la manera correcta de vivir, entonces obviamente la naturaleza de tal preocupación debe estar profundamente influida por el concepto de vida que va a parar a la muerte. La actitud de uno hacia la propia vida es, al mismo tiempo, una actitud hacia la propia muerte. ${ }^{91}$

También la masculinidad o la feminidad no son meros componentes de la vida, sino sus modos, maneras de experimentar el mundo, por lo que la forma que adoptan las relaciones afectivas y eróticas entre los sexos son de importancia fundamental para el significado que cada uno atribuye a su vida. Por último, por el hecho del nacimiento -el cual no es un acontecimiento en mi vida, como no lo es mi muerte- "mi vida adquiere ciertos límites éticos

90 Peter Winch, Comprender una sociedad primitiva, Paidós, Barcelona, 1994.

91 Ibid., p. 82. 
independientemente de mi voluntad, mantengo desde el principio relaciones específicas con otras personas, de las cuales surgen obligaciones que no pueden sino ser éticamente fundamentales". ${ }^{92}$ Como ha observado $\mathrm{N}$. Sánchez Durá al comentar las concepciones de Winch, si se trata por medio de estas nociones límites comunes de formular una especie de estructura, razón o "lógica", debería pensarse, al modo de Wittgenstein, en una especie de lógica primitiva o sensible común a la humanidad y los animales: "En este punto quiero observar al ser humano como un animal: [...] como un ser en estado primitivo. No nos hemos de avergonzar de una lógica que es suficiente para un modo primitivo de comunicación. El lenguaje no ha surgido de un razonamiento." 93 Sin embargo, ya observamos que para Winch es particularmente en la vida humana que estos modos inherentes a la vida adquieren significaciones éticas. Ahora bien, si estas nociones no pueden proveernos "criterios" últimos para zanjar discusiones morales al modo de una "naturaleza humana" a la que fueran inherentes ciertos derechos y deberes - Winch subraya que a este respecto la discusión debe extenderse siempre sobre un horizonte abierto y no clausurado por la suposición falaz de "lo que es o no posible para los seres humanos"- 94 sí en cambio pueden hacer posible un encuentro con otros modos de vida del que resulte algo similar a una "sabiduría" moral. Puesto que al encontrarnos con otras comunidades y formas de vida "no nos hallamos sólo frente a técnicas diferentes, sino a nuevas posibilidades de lo bueno y lo malo en relación con las cuales los hombres pueden adaptarse a la vida", "el concepto de aprender de que está implicado en el estudio de otras culturas claramente vinculado al concepto de sabiduría". 95

Por último, nos referiremos a otros desarrollos que comparten con los ya tratados la búsqueda, tras el reconocimiento de las diferencias, de una "comunidad" basada en un primario nivel carnal de la experiencia. Continuando lo sugerido en este sentido principalmente por Merleau-Ponty y E. Lévinas, Alphonso Lingis se ha propuesto esta investigación en numerosos trabajos tales como "El imperativo elemental", "Nosotros mortales", o, precisamente La comunidad de los que no tienen nada en común. ${ }^{96}$ Nos referiremos a algunos resultados de su reflexión, el primero de ellos concerniente

92 Ibid., p. 85.

93 L. Wittgenstein, Sobre la certeza, §475, Gedisa, Barcelona, 1988, cit. por N. Sánchez Durá, op. cit., p. 275.

94 P. Winch, "Naturaleza humana", op. cit., p. 167.

95 P. Winch, "Comprender una sociedad primitiva", op. cit., p. 78.

96 Alphonso Lingis, "The Elemental Imperative", Reserch in Phenomenology, XVIII, 1988, "We Mortals", Philosophy Today, vol. 35, no. 2, verano 1991, The Community of Those Who Have Nothing in Common, Bloomington and Indianapolis, Indiana University Press, 1994. 
a la cuestión de la comunicación. Como ya observamos más arriba, si bien el problema de la inconmensurabilidad del sentido no puede reducirse al modelo de la intraducibilidad de lenguajes, sí en cambio es posible afirmar que la diversidad de la experiencia vivida se refleja en el ámbito lingüístico y conceptual en el modo de la incomunicación. En su obra acerca de La Communication ${ }^{97}$ Michel Serres ha sostenido que el acceso a la comunicación significa la extracción de un mensaje a partir del ruido de transfondo y el "ruido interno" al mensaje - pongamos como ejemplo de esto último las particularidades de la caligrafía, los acentos regionales, los timbres y temblores de cada voz, en suma, las peculiaridades inherentes al elemento material o sensible del mensaje. La comunicación adquiere así la forma de una lucha contra la contaminación del ruido. Este esfuerzo por silenciar o eliminar no al interlocutor sino a este tercer término exterior que es el ruido, es el que se continúa y se refina tanto en la abtracción que funda a la filosofía como búsqueda de lo universal, como en la idealización científica que atiende a las propiedades del triángulo más allá de su siempre imperfecta representación: en ambos casos se trata de desmaterializar el sentido al máximo, abstraer todo resabio de particularidad y alcanzar el ideal de la comunicación más transparente posible. La fundación que Husserl reconoció en la antigua Grecia del proyecto filosófico y científico de la razón como idealmente extensible a toda la humanidad, es a la vez desde esta perspectiva un esfuerzo por silenciar al máximo el murmullo del mundo fundando así "una república ideal de comunicación universal", una "ciudad máximamente purgada de ruido". Alternativamente a esta visión, A. Lingis se preguntará si cierto tipo de comunicación no se da, más que a pesar o contra el ruido del mensaje, en el ruido mismo. En cuanto somos causas eficientes de la enunciación del mensaje y nos son esenciales ciertas particularidades, perspectivas o puntos de vista y capacidades distintivas, somos parte del ruido. ¿Y no existe también comunicación en la audición del ruido -el ritmo, el tono, la periodicidad, el acento, la vacilación, el balbuceo, el timbre, los silencios- en la voz del otro, en el "ruido de la vida" que se hace oír en risas, llanto, gritos, murmullos? Es en este nivel más primitivo y sensible que el de las significaciones codificadas donde, al contrario de Serres, Lingis intenta hallar una especie de ámbito de comunicación universal fundado, paradójicamente, en las peculiaridades "materiales" de los hablantes. Este nivel "elemental" no solamente reúne a la diversidad humana sino que comunica, más allá incluso de lo humano, con la extrañeza del mundo natural. Merleau-Ponty adelantaba una consideración semejante del lenguaje cuando afirmaba que "como el cristal, el metal, y muchas otras

97 M. Serres, Hermes I: La communication, Les Editions de Minuit, París, 1968. 
sustancias, soy un ser sonoro".98 En la visión de Lingis, sólo un modelo restringido de la comunicación como aquel del que da cuenta $M$. Serres se establece con base en la exclusión y da pie a una diferencia insalvable con el extraño, quien es excluido del sentido como bárbaro, ignorante, bruto, místico, salvaje, monstruo, animal. Primariamente "la comunicación tiene lugar cuando la vibración de la tierra, los océanos y el cielo es acogida, condensada y desplegada en las cavidades de nuestro cuerpo y luego liberada, y cuando oímos su eco retornar con el viento y el mar". 99 La comunicación se daría entonces originariamente con el ruido; propiamente es la vibración de todas las cosas - graznidos, rugidos, gemidos que prolongan el crepitar de las ramas, el silbido del viento, el murmullo del agua que corre-, es decir, el ruido mismo, el que es comunicado.

Existen ciertas situaciones límite -frente al amor o a la muerte, por ejemplo- en que el lenguaje se muestra inútil o impotente y aun es necesario decir algo; situaciones cuando no importa qué es lo dicho, sino el decir mismo; cuando importa más el calor y el tono de la voz que el mensaje. Estas situaciones señalan no sólo los confines del lenguaje sino también su origen. Allí no habla el ego como representante intercambiable del discurso racional o de la razón universal

con sus categorías a priori y formas a priori de organización de las impresiones sensibles. Lo que habla es alguien en su materialidad como terrestre; alguien que respira, suspira y vocaliza en el rumor de la ciudad y los murmullos de la naturaleza; alguien cuya sangre está caliente con el calor del sol y los ardores de la noche. Alguien cuya carne está hecha de tierra - polvo que volverá al polvo- que se yergue frente a otro con el sostén de la tierra alzándose en él o en ella; alguien cuyo rostro está hecho de luz y sombra y cuyos ojos están hechos de luz y lágrimas. ${ }^{100}$

La comunidad a la que corresponde este nivel primario de la comunicación no es la que resulta del reconocimiento del parentesco (kinship) entre humanos que se asocian mediante compromisos recíprocos, intercambio de mensajes, recursos y servicios - lo que es siempre paralelo a la identificación de otros individuos como extraños-, sino entre individuos destituidos en su condición de mortales, una "comunidad en la muerte". Primeramente, es en mi carnalidad mortal que reconozco la alteridad del otro: "es la pared de la propia muerte la que circunscribe la zona de posibilidades que son posibles para mí y las separan de las que lo son para otros. [...] Es en este diferirse

98 M. Merleau-Ponty, Lo visible y lo invisible, op. cit., p. 179.

99 Alphonso Lingis, "The Murmur of the World", en The Community of Those Who Have Nothing in Common, op. cit., pp. 97, 98.

100 A. Lingis, "The Elemental That Faces", op. cit., p. 117. 
de su muerte en relación con la mía que el otro es diferente". ${ }^{101}$ Ahora bien, es también en virtud de compartir ese enigmático colapso del sentido que a la vez nos separa, que se establece más profundamente una comunidad en la separación, una "comunidad de los que no tienen nada en común". En este encuentro sensible con el rostro, la piel, los ojos desnudos del otro, "sentimos la vulnerabilidad y la mortalidad en los temblores del placer que se consume y en la angustia del dolor que agita esas superficies", ${ }^{102}$ y esa vulnerabilidad y mortalidad ajenas nos interpelan con un imperativo. Las superficies carnales se exponen y nos obligan, pero a la vez nos cohartan la posibilidad de ejercer nuestros poderes, de clausurar su sentido en un proyecto. En el acompañamiento de alguien que está muriendo, la caricia del consuelo "es una solicitud que no tiene idea de qué hacer o de cómo escapar; se va hacia donde no se puede avanzar, donde nada se ofrece y nada se promete [...] Se va porque uno se encuentra obligado a ir". ${ }^{103}$ Esta comunidad elemental fundada en nuestra carnalidad mortal no se limita, en fin, a la esfera de la humanidad, en cuanto

en la duración y la paciencia de esta pasividad —escribe Lingis- uno se acerca a todos los que sufren y mueren, a los hambrientos, torturados y masacrados, a los grandes elefantes que mueren en los pantanos y los gorriones que mueren en el frío, a las mariposas que mueren en el sol y los animales amadrigados que mueren en la oscuridad de la tierra, a las estrellas solitarias que mueren en los vacíos del universo, a los dioses asirios y africanos que mueren mientras los desiertos crecen y los dioses mayas que mueren mientras los bosques arden. ${ }^{104}$

Recibido: 6 de octubre de 1999

101 A. Lingis, "Community in Death", op. cit., p. 171.

102 Ibid., p. 177.

103 Ibid., p. 179.

104 Ibid. 